\title{
Evaluation of TRMM Multisatellite Precipitation Analysis in the Yangtze River Basin with a Typical Monsoon Climate
}

\author{
Zengxin Zhang, ${ }^{1,2}$ Qiu Jin, ${ }^{1}$ Xi Chen, ${ }^{3}$ Chong-Yu Xu, ${ }^{4,5}$ Sheng Chen, \\ Elica M. Moss, ${ }^{7}$ and Yuhan Huang ${ }^{1}$ \\ ${ }^{1}$ Joint Innovation Center for Modern Forestry Studies, College of Biology and the Environment, Nanjing Forestry University, \\ Nanjing 210037, China \\ ${ }^{2}$ State Key Laboratory of Satellite Ocean Environment Dynamics, Second Institute of State Oceanic Administration, \\ Hangzhou 310012, China \\ ${ }^{3}$ State Key Laboratory of Hydrology-Water Resources and Hydraulics Engineering, Hohai University, Nanjing 210098, China \\ ${ }^{4}$ State Key Laboratory of Water Resources and Hydropower Engineering Science, Wuhan University, Wuhan 430072, China \\ ${ }^{5}$ Department of Geosciences, University of Oslo, 0316 Oslo, Norway \\ ${ }^{6}$ Hydrometeorology and Remote Sensing Laboratory and School of Civil Engineering and Environmental Science, \\ University of Oklahoma, Norman, OK 73072, USA \\ ${ }^{7}$ Department of Biological and Environmental Sciences, Alabama A\&M University, Normal, AL 35762, USA
}

Correspondence should be addressed to Zengxin Zhang; nfuzhang@163.com

Received 15 March 2016; Revised 29 July 2016; Accepted 25 October 2016

Academic Editor: Roberto Fraile

Copyright (C) 2016 Zengxin Zhang et al. This is an open access article distributed under the Creative Commons Attribution License, which permits unrestricted use, distribution, and reproduction in any medium, provided the original work is properly cited.

Satellite-based precipitation products are expected to offer an alternative to ground-based rainfall estimates in the present and the foreseeable future. In this paper, we evaluate the performance of TRMM 3B42 precipitation products in the Yangtze River basin for the period of 2003 2010. The results are as follows: (1) the performance of RTV7 (V7) products is generally better than that of RTV6 (V6) in the Yangtze River basin, and the percentage of best performance (bias ranging within $-10 \% \sim 10 \%$ ) for the annual mean precipitation increases from $21.72 \%$ (54.79\%) to $36.70 \%$ (59.85\%) as the RTV6 (V6) improved to the RTV7 (V7); (2) the TMPA products have better performance in the wet period than that in the dry period in the Yangtze River basin; (3) the performance of TMPA precipitation has been affected by the elevation and a downward trend can be found with the increasing elevation in the Yangtze River basin. The average CC between the V7 and observed precipitation in July decreases from 0.71 to 0.40 with the elevation of gauge stations increasing from $500 \mathrm{~m}$ below to $4000 \mathrm{~m}$ above in the Yangtze River basin. More attention should be paid to the influence of complex climate and topography.

\section{Introduction}

Seasonal and interannual climate variability in the subtropical humid monsoon region is mainly determined by changes in precipitation [1]. Accurate precipitation data with high spatial and temporal resolution are deemed necessary for various fields of research, such as climate change, water resources management, and meteorological disaster prevention [25]. Although rain gauges are considered as the standard for measuring precipitation, the rain gauge network is still insufficient across large areas worldwide, and the remotely sensed information about precipitation becomes one of the main sources of reliable and continuous data $[6,7]$. Thus satellite-based precipitation products are expected to offer an alternative to ground-based precipitation estimates in the present and the foreseeable future [8]. For this purpose, the quality and applicability of satellite-based precipitation products need to be evaluated [9].

Satellite-based precipitation products offer a potential alternative or supplement to ground-based rainfall estimates over sparsely gauged or ungauged basins $[6,7,10-13]$. As the Tropical Rainfall Measuring Mission (TRMM) satellite completes more than a decade of operation, it has provided researchers throughout the world with a large volume of 
rainfall data for the validation of atmospheric and climate models [14]. The TRMM products include the near-real-time products, that is, 3B42RT Version 6 and Version 7 (hereafter RTV6 and RTV7) estimates and the research products of 3B42 Version 6 and Version 7 (hereafter V6 and V7) estimates $[15,16]$. TRMM rainfall products have been widely used in the fields of hydrology, meteorology, and agricultural science [17-19].

In recent years, comparisons between the TRMM rainfall products and rain gauge observations have been made in different climate regions in the world [20-25]. Tong et al. [26] revealed that the TRMM 3B42V7 precipitation data have a better performance than that of RTV7 and PERSIANN in different climate zones. Collischonn et al. [27] found that the TRMM 3B42 rainfall data could be considered reliable in the Tapajo's basin and Amazon basin, Brazil. For the RTV6 and RTV7 products, Chen et al. [14] showed that the TRMM 3B42RT rainfall data had a high precision and a good correlation with the observed precipitation in the humid subtropical Pearl River basin, China, at the basin scale. For the V6 and V7 products, Gu et al. [28] found that the V6 rainfall product was reliable and had good precision in the Yangtze River basin, China, and the TRMM rainfall data estimates could well represent the seasonal changes between wet and dry periods. Chen et al. [29] reported that V7 was adequate at detecting intense tropical cyclone rainfall in the tropic Pacific basin. Zhao et al. [30] also found that there were good linear relationships between $\mathrm{V} 7$ and rain gauge data in the arid and humid transition region-Weihe River catchment, Yellow River basin.

Differences between the near-real-time products (RTV6 and RTV7) and research products (V6 and V7) have been reported. Qiao et al. [31] assessed the successive V6 and V7 TMPA (TRMM multisatellite precipitation analysis) rainfall products over the climate-transitional zone in the southern Great Plains, USA. As the V7 products are likely to be the last ones for TMPA data released in early 2013, V7 corrects the widespread rainfall underestimation from V6, and this improvement was more pronounced in the relatively dry basin. Yong et al. [32] reported that V7 product generally performs better than the original V6 over the high-latitude Laohahe basin and the low-latitude Mishui basin at both daily and monthly scales. Xue et al. [19] revealed that the V7 algorithm had significantly upgraded from V6 in precipitation accuracy.

However, accuracy of the TRMM precipitation data varies in different areas and seasons and across different spatiotemporal scales. Khan et al. [33] suggested that the best agreement between the V7 and gauge observations with correlation coefficient values ranged from moderate $(0.4)$ to high $(0.8)$ over the spatial domain of Pakistan, and the seasonal variation of rainfall frequency had large biases $(100 \%$ 140\%) over high latitudes $\left(36^{\circ} \mathrm{N}\right)$ with complex terrain for daily, monsoon, and premonsoon comparisons. Habib et al. [34] reported that the TMPA products tended to overestimate small rain rates and underestimate large rain rates over Louisiana, USA. Islam and Uyeda [35] found that 3B42 rainfall data overestimated the rainfall during the premonsoon period in dry regions but underestimated it during the monsoon period in wet regions over Bangladesh. Li et al. [36] stated that daily TRMM rainfall data could not describe the occurrence and contribution rates of precipitation accurately in Poyang Lake basin, China. Almazroui [37] highlighted a general overestimation in the satellite products over Saudi Arabia. Liu [38] examined the differences between V6 and V7 on a global scale and found that although both V6 and V7 showed a good agreement in moderate and heavy rain regimes, there existed systematic differences between them. Thus, more studies are of importance in further understanding the impacts of climate and topography on the evaluation of TMPA products in the world.

The Yangtze River originates from the Qinghai-Tibet Plateau and flows across three distinct terrains from the headwater region to the East China Sea at Shanghai city, with a 7000 m elevation drop [39]. Most of the Yangtze River basin is dominated by the subtropical monsoon climate [39]. The Yangtze, the longest river in China, has been subjected to flooding throughout history [40]. Although there are hundreds of gauge stations in the Yangtze River basin, the gauge network is still insufficient in the basin especially in the upper Yangtze reaches due to its high elevation and complex terrain [41]. Additionally, the most widely used rain gauge stations are distributed sparsely and unevenly $[42,43]$. Several studies have been made in the Yangtze River basin in evaluating the performance of the TMPA products. For example, Hao et al. [41] reported that TRMM RTV7 significantly overestimates the precipitation over the upper Yellow and Yangtze River basins. Gao and Liu [40] also found that the TMPA products had better agreement with gauge measurements over humid regions than that over arid regions in the Tibetan Plateau. Moreover, biases of TMPA present weak dependence on topography, while biases of TMPA RT present dependence on topography which indicated that topography and variability of elevation and surface roughness played important roles in explaining the bias of TMPA products.

Although the TRMM multisatellite precipitation data have been extensively evaluated in many areas in recent years, the knowledge of the impacts of complex topography on the precipitation in a humid monsoon area is limited [8]. The scientific questions to be investigated in this paper include the following: (1) does the V7 improve the precipitation evaluation in the Yangtze River basin compared to V6? (2) do the different monsoon climates impact the precipitation precision in the upper and mid-lower Yangtze reaches? (3) do the different topographies between plateau region and the East China plains have significant influence on the precipitation precision of the TMPA products in the Yangtze River basin? In this study, we attempt to address these problems based on thorough analysis of observed and TMPA precipitation datasets over the Yangtze River basin. This study is of importance in further understanding the impacts of monsoon and complex topography on the precipitation assessment in a large river basin scale.

\section{Data and Methods}

2.1. Study Area. The Yangtze River is the longest river in China and the third longest river in the world. The river is about $6300 \mathrm{~km}$ long and the basin lies between latitudes 
$24^{\circ} \mathrm{N}$ and $36^{\circ} \mathrm{N}$ and longitudes $90^{\circ} \mathrm{E}$ and $122.5^{\circ} \mathrm{E}$ with an area of $1,800,000 \mathrm{~km}^{2}$ that accounts for about one-fifth of China's territory [28]. The annual mean gross amount of water resources of the Yangtze River basin is $976 \mathrm{~km}^{3}$ [44]. The importance of the Yangtze River lies not only in its geographical position, sheer size, and complex geomorphology, but also in the way that the river plays an important role in the regional water cycle, energy balance, climate change, and ecosystems as well as in China's economic and social development [39]. Three types of monsoon prevail in the Yangtze River basin. In winter, the entire Yangtze River basin is under the control of the Siberian northwest monsoon. In summer, the East Asia monsoon predominantly influences the middle and lower reaches, while the Indian southwest monsoon mainly influences the upper reaches. The Indian and the East Asian monsoon systems are independent of each other and, at the same time, interact with each other $[45,46]$. Climatically, the southern part of the basin is adjacent to the tropical zone and the northern part is close to the temperate zone, across the low-latitude region and mid-latitude region.

2.2. Precipitation Data. The TMPA precipitation estimates are based primarily on a combination of microwave (MW) and merging infrared (IR) estimates from multiple satellites [34]. The 3B42 TMPA datasets used in this study were downloaded from the NASA website (https://trmm.gsfc.nasa .gov/). It has a high temporal $(3 \mathrm{~h})$ and spatial $\left(0.25^{\circ} \times\right.$ $0.25^{\circ}$ ) resolution. The $3 \mathrm{~B} 42 \mathrm{TMPA}$ dataset is available in two versions: a research-quality product (3B42) released 10 15 days after each month, covering the global latitude belt from $60^{\circ} \mathrm{N}$ to $60^{\circ} \mathrm{S}$, and a near-real-time product (3B42RT), which is released approximately $9 \mathrm{~h}$ after real-time with the coverage of the latitude belt from $50^{\circ} \mathrm{N}$ to $50^{\circ} \mathrm{S}$. The main differences between the two versions are the use of the rain gauge data for bias reduction, which are unavailable in the real-time products $[34,47]$.

Daily rainfall data of eight years (2003 2010) from 224 rain gauge stations in the Yangtze River basin shown in Figure 1 is compared with the TRMM rainfall data to evaluate the quality of TRMM rainfall estimates at different spatial and temporal scales. The readers should bear in mind that the gauges used in the observed precipitation might not be completely independent of those used in V6/V7 since data from some rain gauge stations could be in both of datasets according to the China Meteorological Administration.

2.3. Statistical Indices. Statistical indices are widely used to evaluate the performance of TMPA precipitation products against the rain gauges; four validation statistical indices are selected in this study. These are the relative bias (Bias), correlation coefficient (CC), root mean square error (RMSE), and Error, defined, respectively, by the following equations:

$$
\begin{aligned}
& \text { Bias }= {\left[\frac{\sum_{i=1}^{n} \mathrm{SIM}_{i}-\sum_{i=1}^{n} \mathrm{OBS}_{i}}{\sum_{i=1}^{n} \mathrm{OBS}_{i}}\right] \times 100 \%, } \\
& \mathrm{CC}=\frac{\sum_{i=1}^{n}\left(\mathrm{OBS}_{i}-\overline{\mathrm{OBS}}\right) \sum_{i=1}^{n}\left(\mathrm{SIM}_{i}-\overline{\mathrm{SIM}}\right)}{\sqrt{\sum_{i=1}^{n}\left(\mathrm{OBS}_{i}-\overline{\mathrm{OBS}}\right)^{2} \sum_{i=1}^{n}\left(\mathrm{SIM}_{i}-\overline{\mathrm{SIM}}\right)^{2}}},
\end{aligned}
$$

$$
\begin{aligned}
\text { RMSE } & =\sqrt{\frac{\sum_{i=1}^{n}\left(\mathrm{OBS}_{i}-\mathrm{SIM}_{i}\right)^{2}}{n}}, \\
\text { Error } & =\mathrm{OBS}_{i}-\mathrm{SIM}_{i},
\end{aligned}
$$

where $\mathrm{OBS}_{i}$ is the observed precipitation; $\mathrm{SIM}_{i}$ is the TMPA precipitation; $\overline{\mathrm{OBS}}$ denotes the mean of the gauge station precipitation; $\overline{\text { SIM }}$ denotes the mean of the TMPA precipitation; and $n$ is the amount of daily precipitation in the analysis.

\section{Results}

3.1. Spatial and Temporal Variation of TMPA Products in the Yangtze River Basin. Figure 2 shows the spatial distribution of annual mean precipitation in Yangtze River basin from observed and TMPA data during the period of 2003 2010. Observed annual mean precipitation decreases from southeast $(>2000 \mathrm{~mm} / \mathrm{a})$ to northwest $(<400 \mathrm{~mm} / \mathrm{a})$ (Figure $2(\mathrm{e})$ ). Comparatively, the spatial distributions of precipitation of the V6 and V7 (Figures 2(b) and 2(d)) are similar to that of observed precipitation (Figure 2(e)) and the percentage of best performance (bias ranges from $-10 \%$ to $10 \%$ ) reaches $54.79 \%$ and $59.85 \%$ for V6 and V7, respectively (Table 1 ). However, both of the RTV6 and RTV7 tend to overestimate precipitation over the upper Yangtze River basin and the percentage of overestimating (bias > 50\%) reaches 29.74\% and $33.51 \%$ for the RTV6 and RTV7, respectively. While they underestimate precipitation in the middle and lower Yangtze River basin, the percentage of underestimating (bias $<-10 \%$ ) for the RTV7 in the middle and lower Yangtze River basin is $12.14 \%$ while it sums up to $79.11 \%$ for the RTV6.

The relative precipitation bias of the TMPA estimates against the interpolated observed data for the average annual precipitation is shown in Figure 3. The larger positive precipitation bias can be found in the upper Yangtze reaches and negative precipitation bias appears in the mid-lower Yangtze reaches for the RTV6 product (Figure 3(a)), and the performance of the RTV7 has been significantly improved in comparison with that of RTV6 in terms of magnitude of the bias (Figure 3(c)). For example, the percentage of best performance (ranging within $-10 \% \sim 10 \%$ ) for the RTV7 product is $36.70 \%$, which is higher than that of the RTV6 with the percentage of $21.72 \%$ over the entire Yangtze River basin (Table 1). It also shows that, in the mid-lower Yangtze reaches, the best performance for the RTV7 is much better than that of the upper Yangtze reaches. In other words, there has been a marked improvement for the RTV7 in the mid-lower Yangtze reaches and an improvement for the evaluation of the RTV7 in the upper Yangtze reaches compared with that of the RTV6 products. Not surprisingly, both the V6 and V7 (Figures 3(b) and 3(d)) have similar spatial patterns of precipitation biases in the Yangtze River basin and most of the precipitation bias ranges from $-10 \%$ to $10 \%$ for both of them (Table 1).

Figure 4 shows the changes of monthly mean precipitation for the observed and TMPA products in the Yangtze River basin from 2003 to 2010 . It can be seen that both the V6 and V7 products capture the seasonal variabilities of the observed precipitation better than that of the RTV7 


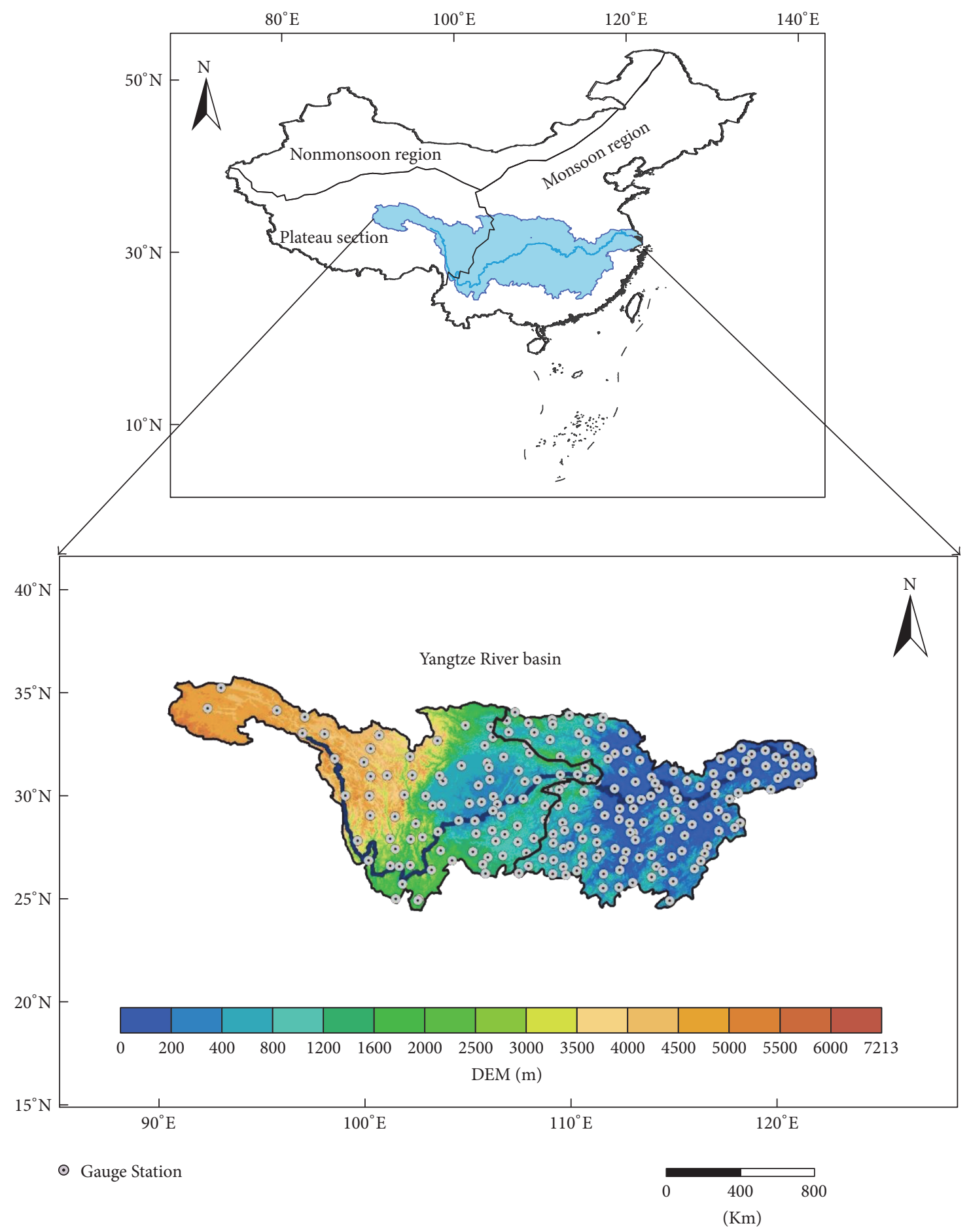

FIGURE 1: Location of the Yangtze River basin and gauge stations.

and RTV6 products do. The RTV7 and the RTV6 products overestimate the precipitation in the upper Yangtze reaches especially in the dry period, while underestimating the precipitation in the mid-lower Yangtze reaches.

For the monthly mean precipitation between the observed and TMPA products (Figure 5), it is clear that the observed monthly precipitation maximum appears in June in the mid-lower Yangtze reaches and one month earlier than that in the upper Yangtze reaches. All of the TMPA products agree well with the monthly changes of the observed precipitation in the Yangtze River basin. However, the RTV6 product overestimates precipitation in winter and spring in the upper Yangtze reaches and the RTV7 overestimates precipitation in summer in the mid-lower Yangtze reaches. 


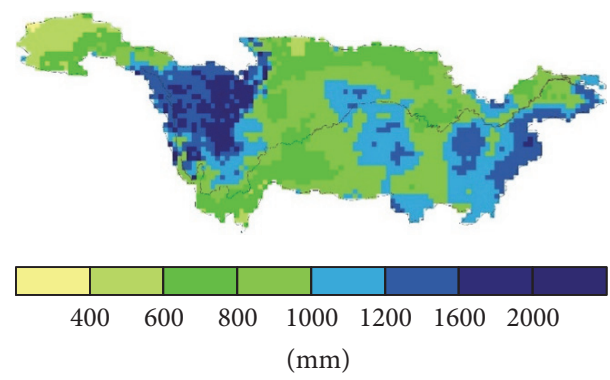

(a) 3B42 RTV6

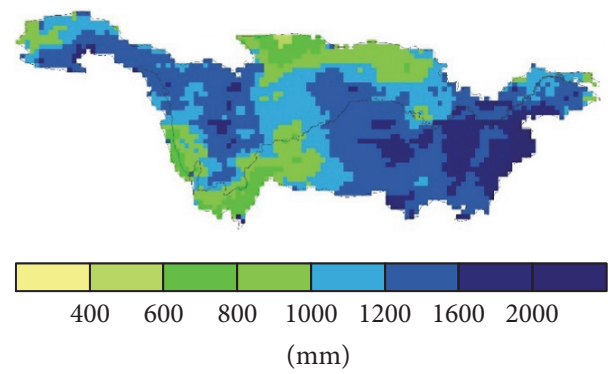

(c) 3B42 RTV7

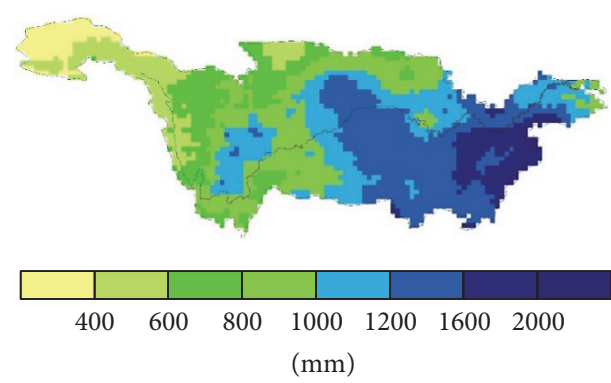

(b) $3 \mathrm{~B} 42 \mathrm{~V} 6$

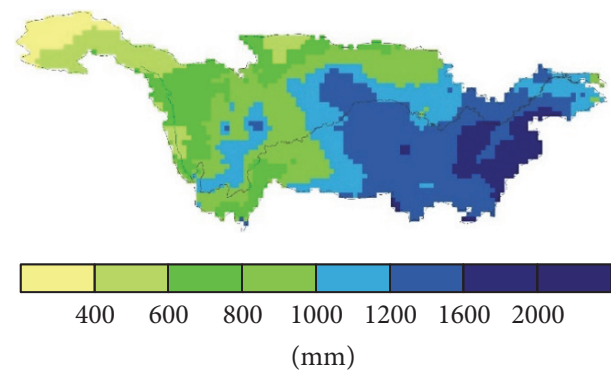

(d) $3 \mathrm{~B} 42 \mathrm{~V} 7$

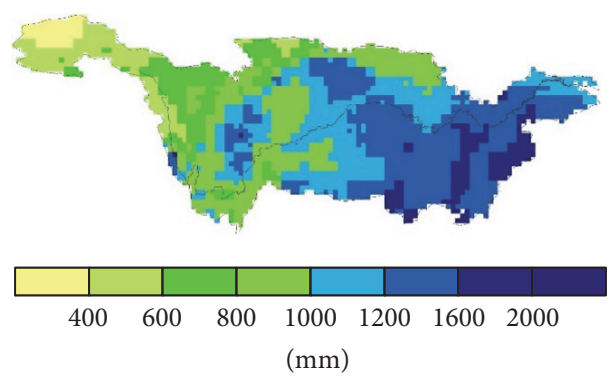

(e) Obs

FIGURE 2: Spatial distribution of average annual precipitation in Yangtze River basin for the TMPA and observed data from 2003 to 2010.

TABLE 1: Distributions of Bias for rainfall estimates from TMPA in the upper Yangtze, mid-lower Yangtze, and the entire Yangtze (Unit: \%).

\begin{tabular}{lcccccccc}
\hline Area & TMPA & $<-50$ & $-50 \sim-31$ & $-30 \sim-11$ & $-10 \sim 10$ & $11 \sim 30$ & $31 \sim 50$ & $>50$ \\
\hline \multirow{5}{*}{ The upper Yangtze } & RTV6 & 0 & 3.44 & 25.56 & 23.60 & 9.91 & 7.75 & 29.74 \\
& V6 & 0.27 & 5.39 & 36.88 & 47.54 & 9.58 & 0.34 & 0 \\
& RTV7 & 0.13 & 0.40 & 12.81 & 24.88 & 20.50 & 7.75 & 33.51 \\
& V7 & 0.13 & 2.90 & 31.09 & 52.66 & 12.88 & 0.27 & 0.07 \\
\hline \multirow{5}{*}{ The mid-lower Yangtze } & RTV6 & 0 & 16.85 & 62.26 & 19.38 & 1.52 & 0 & 0 \\
& V6 & 0 & 0.17 & 18.28 & 63.86 & 17.69 & 0 & 0 \\
& RTV7 & 0 & 0.51 & 11.63 & 51.47 & 30.50 & 5.64 & 0.25 \\
& V7 & 0 & 0.17 & 12.89 & 68.83 & 18.03 & 0.08 & 0 \\
\hline \multirow{5}{*}{ The entire Yangtze } & RTV6 & 0 & 9.40 & 41.87 & 21.72 & 6.18 & 4.31 & 16.52 \\
& V6 & 0.15 & 3.07 & 28.61 & 54.79 & 13.18 & 0.19 & 0 \\
& RTV7 & 0.07 & 0.45 & 12.28 & 36.70 & 24.94 & 6.82 & 18.73 \\
& V7 & 0.07 & 1.69 & 23.00 & 59.85 & 15.17 & 0.19 & 0.04 \\
\hline
\end{tabular}

3.2. Variation of the Precipitation under the Influence of Monsoon Climate. East Asian monsoon is difficult to arrive in the upper Yangtze reaches, especially the headwater areas in the Yangtze River [46]. However, the upper Yangtze reaches are adjacent to the India monsoon regions where the precipitation could be affected by the India monsoon $[39,48]$. Some areas in the upper Yangtze reaches are located in the Tibet Plateau which is affected by the plateau climate. Therefore, the Yangtze River basin is affected by three types of monsoon, winter monsoon, East Asian summer monsoon, 


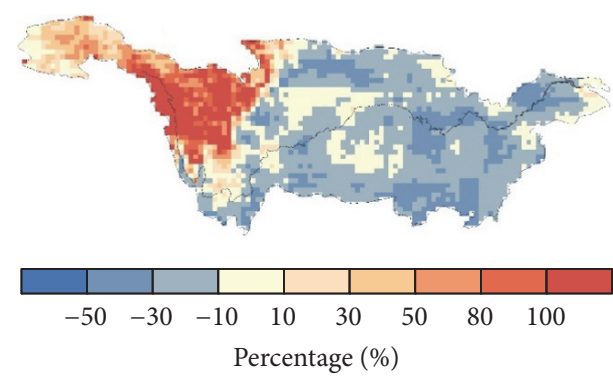

(a) RTV6 minus Obs

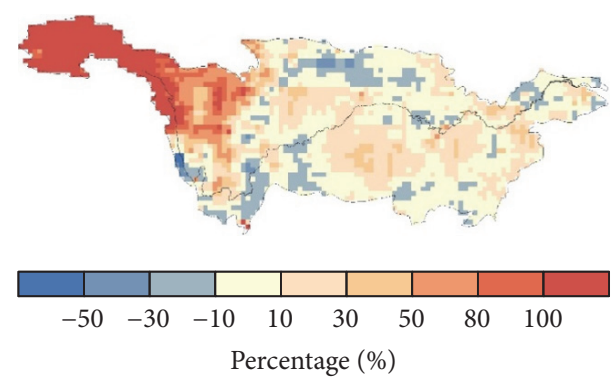

(c) RTV7 minus Obs

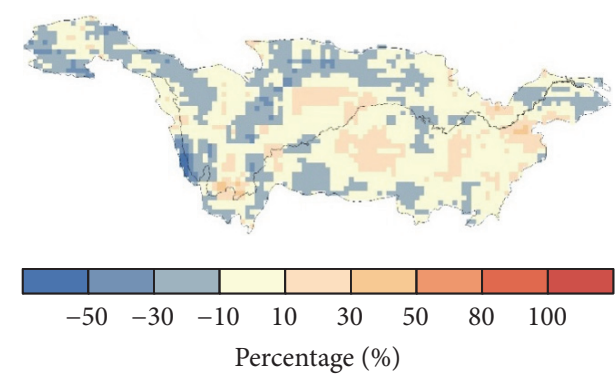

(b) V6 minus Obs

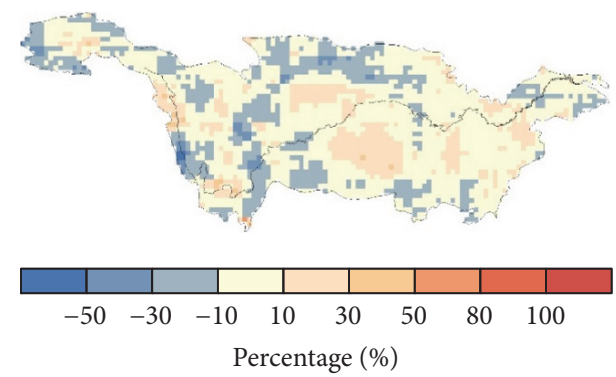

(d) V7 minus Obs

FIGURE 3: The relative bias of the TMPA precipitation estimates against the interpolated observed precipitation data for the average annual precipitation in the Yangtze River basin.

and Indian summer monsoon [49, 50]. In winter, the entire Yangtze River basin is mainly controlled by the Siberian northwest monsoon, while in summer the upper Yangtze reaches are mainly affected by India monsoon, and the midlower Yangtze reaches are usually dominated by the East Asian monsoon. The temporal and spatial distributions of the rain zone in the Yangtze River basin are closely related to monsoon activities and seasonal motion of subtropical highs [51]. Normally, the summer monsoon starts to influence the Yangtze River Basin in April and retreats in October [46]. According to the monthly mean precipitation in the Yangtze River basin during the period of 2003 2010, dry period (from November to March) and wet period (from May to September) were defined in this paper.

Since the Asia monsoon has obviously seasonal variation characteristics, the correlations between TMPA products and observed precipitation in different seasons have been calculated. Figure 6 shows the density-colored scatter plots of TMPA versus observed daily precipitation data for the dry period and wet period in the Yangtze River basin. There are significant correlations between the TMPA products and observed precipitation in the Yangtze River basin (statistically significant at the $99 \%$ confidence level). Higher CC values can be found between the TMPA products and the observed precipitation for each of the TMPA products in the wet periods than that of dry periods in the Yangtze River basin. However, the RSME of the TMPA precipitation estimates against the observed precipitation is generally smaller for the dry periods than that of the wet periods in the Yangtze River basin. It can be found that an obvious improvement of the RTV7 product has been made over the RTV6 product. The correlations between the RTV7 and observed precipitation are higher than that of RTV6 in both the wet periods and dry periods in the upper and mid-lower Yangtze reaches, respectively. Overall, the V7 products have the higher CC value and smaller Bias and RMSE in the wet periods and dry periods than that of V6 product over the Yangtze River basin. Nevertheless, there is still systematic bias for the V7 products as the fitted lines (red lines in Figure 6) deviated from the lines in $45^{\circ}$ angle (blue lines in Figure 6), especially in the upper Yangtze reaches for the dry period.

Figure 7 can be used to further identify the precision of different monsoon precipitation estimates from the TMPA precipitation products, for example, East Asian summer monsoon precipitation seen from Figure 7 in July and located in the lower elevation area (at $500 \mathrm{~m}$ above sea level), Indian summer monsoon seen from Figure 7 in July and located in the Tibet Plateau over $4000 \mathrm{~m}$ above sea level, and the Siberian northwest monsoon seen from Figure 7 in January. Generally, all the TMPA precipitation products give a more reliable estimation of East Asian summer monsoon precipitation (CC ranges $0.39 \sim 0.90$ as for V7) than that of the Indian summer monsoon precipitation (CC ranges 0.27 0.89 as for V7), and the reliability of the TMPA precipitation products in estimation of the Siberian northwest monsoon precipitation decreases as the elevation increases.

3.3. Variation of the Precipitation with Elevation. Evaluation of the TMPA precipitation products with the changes of elevation is also shown in Figure 7. Overall, the performance of TMPA precipitation estimation shows a downward trend with the increasing elevation in the Yangtze River basin in different seasons. Higher correlations between the TMPA products and observed precipitation can be found in the 


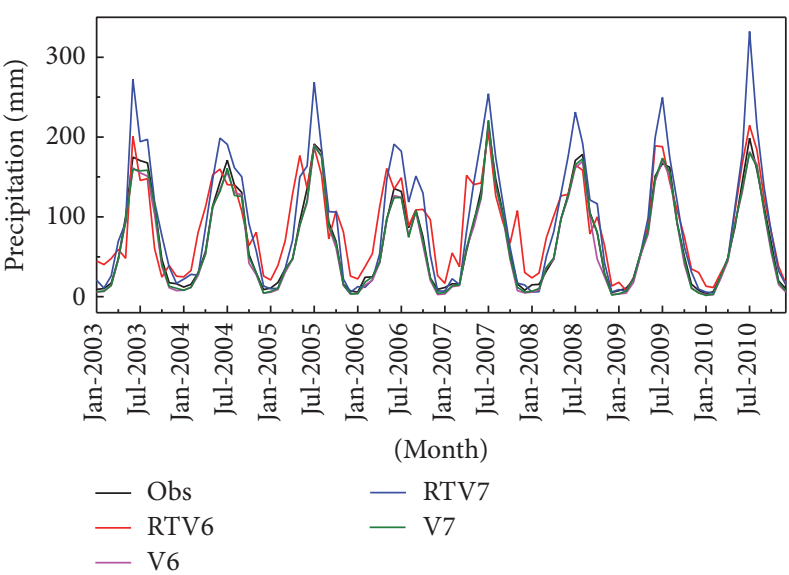

(a) The upper Yangtze

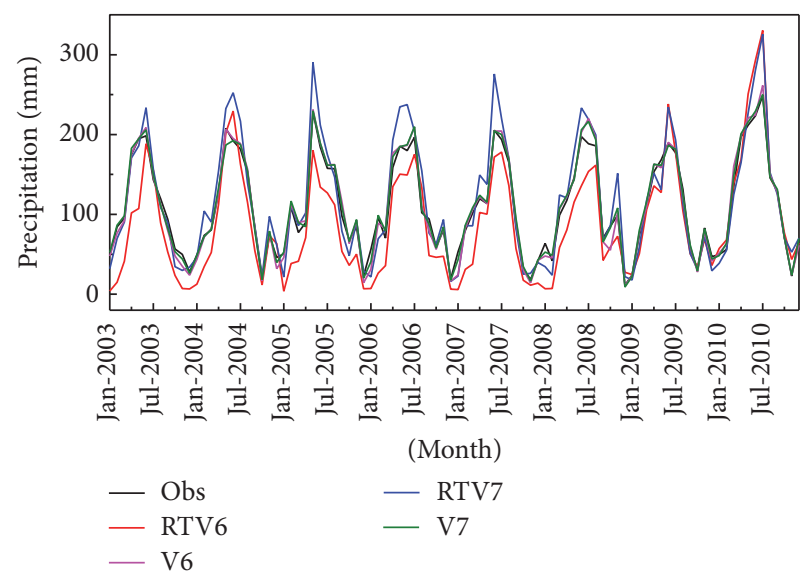

(b) The mid-lower Yangtze

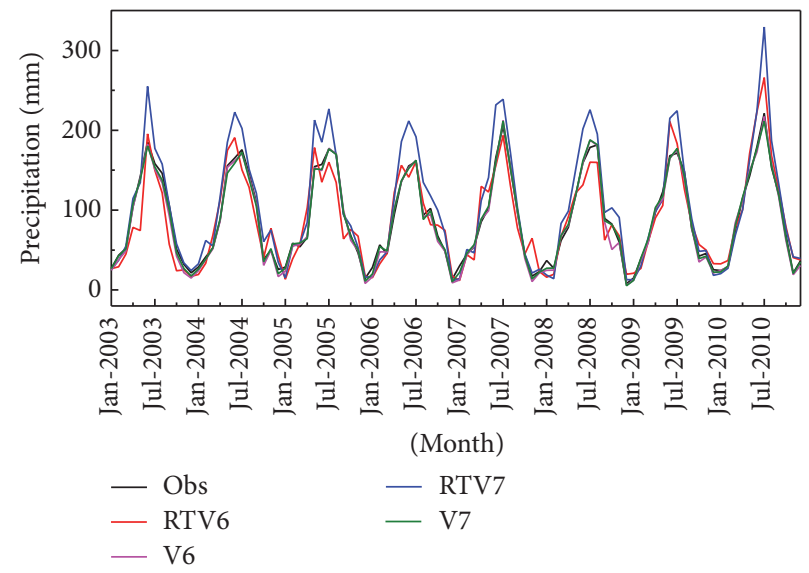

(c) The entire Yangtze

FIGURE 4: The comparison between the monthly observed and TMPA products precipitation from 2003 to 2010. ((a), the upper Yangtze; (b), the mid-lower Yangtze; (c), the entire Yangtze).

lower elevation areas, while lower correlations appear in the higher elevation areas in April, July, and October. Highest correlations between V7 product and observed precipitation can be found in the lower elevation areas in July and its $\mathrm{CC}$ value is as high as 0.90 . As for V7 product, there are 114 stations located in the middle and lower Yangtze River basin within $500 \mathrm{~m}$ above sea level and the CC (V7 versus Obs) ranges $0.48 \sim 0.90$, while 22 stations scatter in this area $500 \mathrm{~m}$ high and the CC ranges $0.39 \sim 0.86$ in July. However, there are 26 stations located in the upper Yangtze River basin $500 \mathrm{~m}$ below with the CC ranging from 0.41 to 0.93 ; 61 stations scatter in this area 500 4000 $\mathrm{m}$ high and the CC ranges $0.27 \sim$ 0.89 , while 6 stations are located $4000 \mathrm{~m}$ high with the CC ranging within $0.27 \sim 0.50$.

Figure 8 shows the changing of correlation coefficient of daily mean TMPA products and observed precipitation data with elevation. It seems that the downward trend of the correlation coefficient is found with the increasing elevation. The most rapid decline is found for RTV6 and the slowest downward trend can be found for V7.

To better understand the changes of CC between the TMPA products and observed precipitation with elevation, the correlations between the TMPA products and observed precipitation of 8 tributaries of the Yangtze River basin were summarized in Table 2. We can find that the correlations appear higher in the lower river basin and then decrease from the lower river basin to the higher river basin as a whole. The lowest correlations appear in the Jinsha River basin with the highest average elevation of $2700 \mathrm{~m}$ above sea level. Moreover, higher correlations can be found in the Jialing River basin with lower elevations, which are also located in the upper Yangtze reaches. It was also found that the performance of TRV7 (V7) is better than that of TRV6 (V6) in both the lower and higher river basins. The results reveal that the impacts of elevation should be considered when using TMPA products.

\section{Discussion}

Precipitation variability becomes essential to reveal the changing features of the monsoon climate as satellite-based precipitation products are highly valued along with the development of the remote sensing technology in recent years $[6,7]$. With the previous analysis results, the TMPA products have become more reliable in estimating the precipitation in 


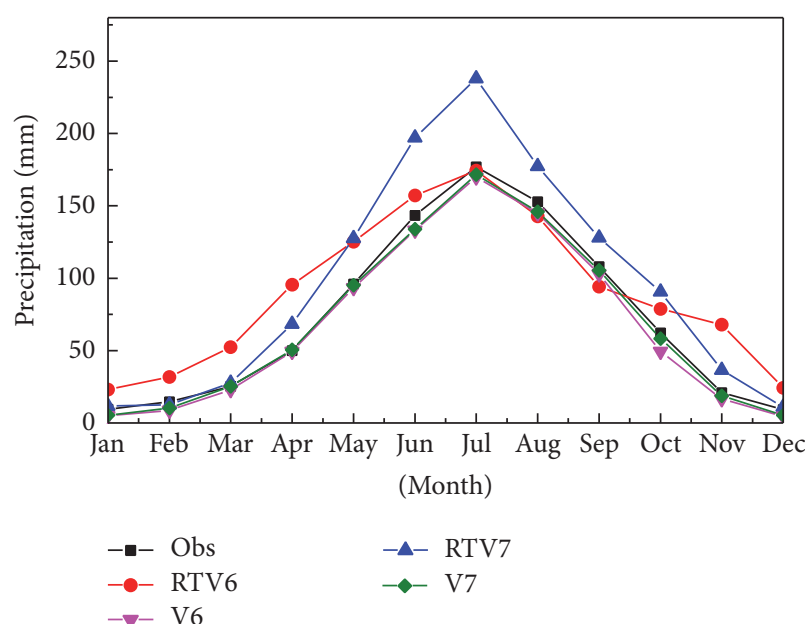

(a) The upper Yangtze

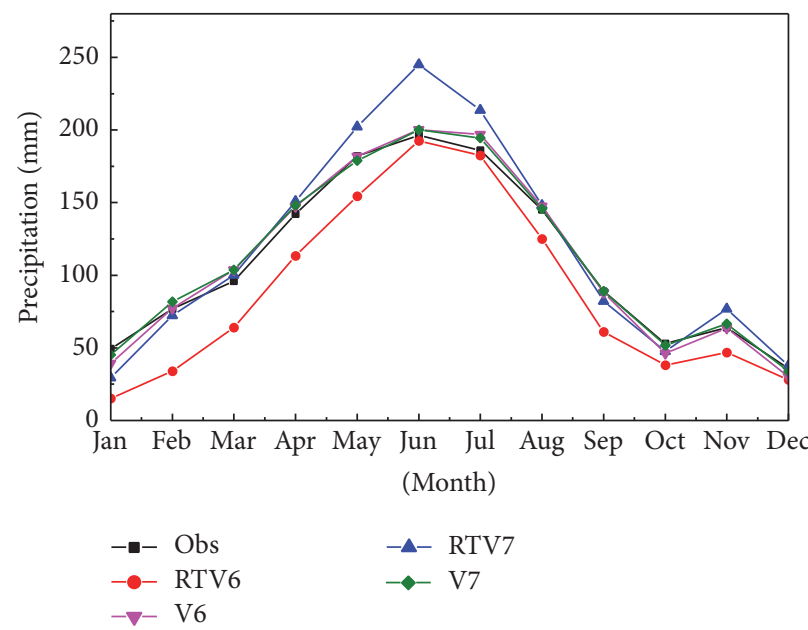

(b) The mid-lower Yangtze

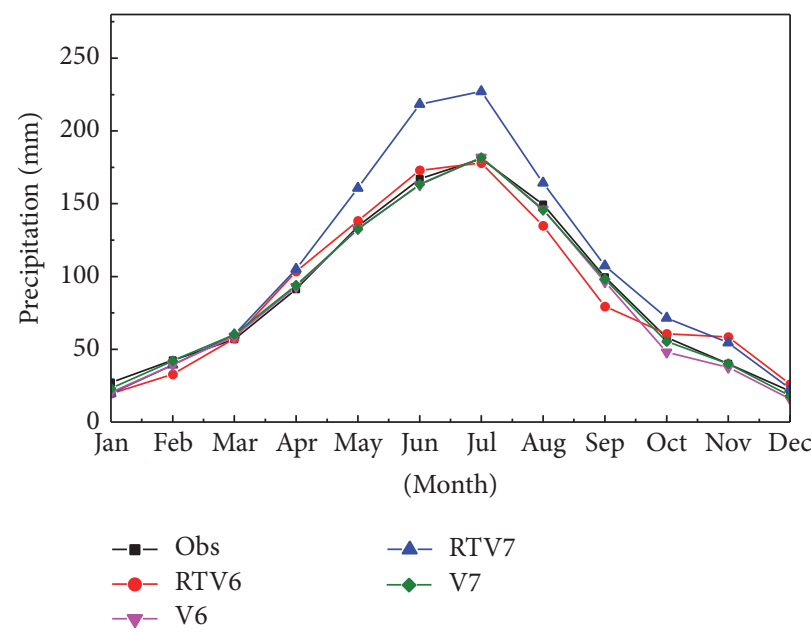

(c) The entire Yangtze

FIGURE 5: The same as Figure 4, but for the average monthly mean precipitation.

TABLE 2: The correlation coefficient between the TMPA products and observed precipitation of 8 tributaries of the Yangtze River.

\begin{tabular}{lcccccccc}
\hline $\begin{array}{l}\text { Tributaries } \\
\text { (elevation, })\end{array}$ & $\begin{array}{c}\text { Taihu Lake } \\
(22)\end{array}$ & $\begin{array}{c}\text { Poyang Lake } \\
(137)\end{array}$ & $\begin{array}{c}\text { Dongting } \\
\text { Lake }(287)\end{array}$ & $\begin{array}{c}\text { Han River } \\
(480)\end{array}$ & $\begin{array}{c}\text { Jialing River } \\
(484)\end{array}$ & $\begin{array}{c}\text { Wujiang } \\
\text { River (1011) }\end{array}$ & $\begin{array}{c}\text { Mintuo River } \\
(1670)\end{array}$ & $\begin{array}{c}\text { Jinsha River } \\
(2713)\end{array}$ \\
\hline RTV6 & 0.51 & 0.62 & 0.60 & 0.61 & 0.63 & 0.61 & 0.54 & 0.48 \\
V6 & 0.63 & 0.68 & 0.69 & 0.68 & 0.70 & 0.69 & 0.64 & 0.61 \\
RTV7 & 0.61 & 0.70 & 0.69 & 0.66 & 0.69 & 0.68 & 0.61 & 0.57 \\
V7 & 0.65 & 0.69 & 0.70 & 0.70 & 0.72 & 0.71 & 0.65 & 0.63 \\
\hline
\end{tabular}

the Yangtze River basin as the RTV6 improved to the RTV7 and the V6 to V7. The performance of the RTV7 (V7) precipitation products is generally better than that of RTV6 (V6), which is in agreement with previous studies. However, there exist systematic differences between TMPA products and observed precipitation. Both of the RTV6 and RTV7 overestimate the annual mean precipitation in the upper Yangtze reaches and they underestimate the precipitation in the midlower Yangtze reaches. However, the percentage of underestimating (bias $<-10 \%$ ) for the RTV7 in the middle and lower Yangtze River basin is significantly less than that of RTV6.
The monsoon climate might have significant impacts on the precipitation evaluation in the Yangtze River basin. The TMPA products have better performance to reveal the features of summer monsoon precipitation than that of winter monsoon in the Yangtze River basin. Higher CC values can be found between the TMPA products and the observed precipitation for each of the TMPA products in the wet periods than that of dry periods in the Yangtze River basin. The V7 product has the higher CC value in the wet period than that of dry period in the Yangtze River basin. Nevertheless, there is still systematic bias for 


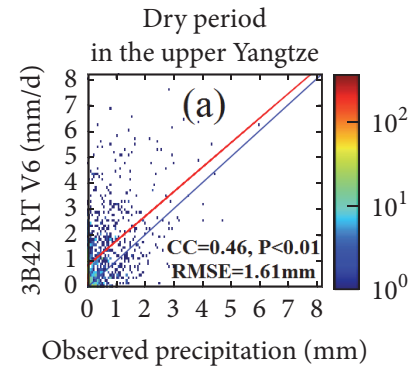

(a)

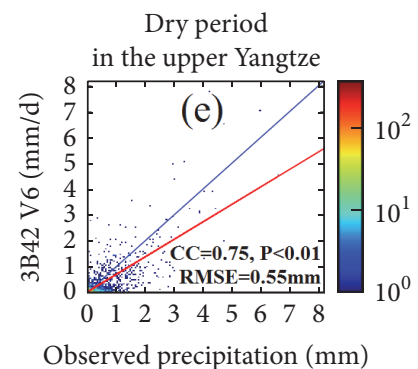

(e)

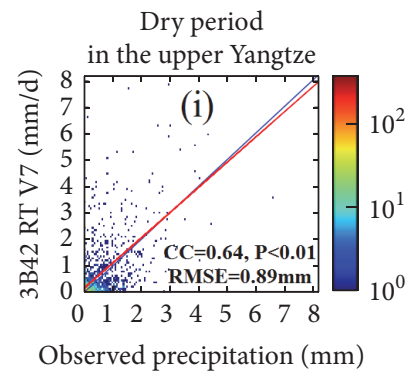

(i)

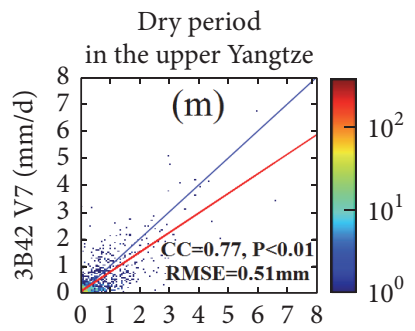

Observed precipitation ( $\mathrm{mm}$ )

(m)

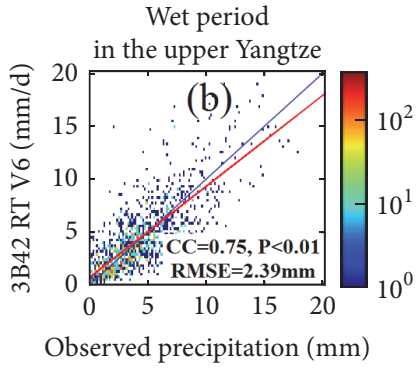

(b)

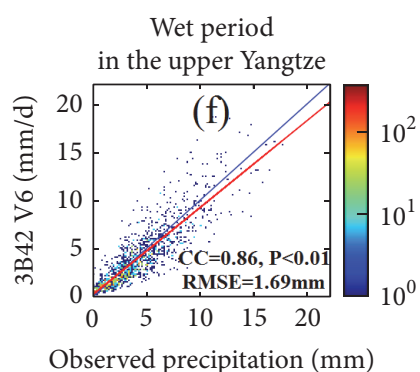

(f)

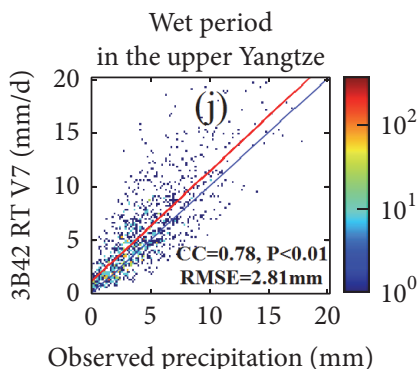

(j)

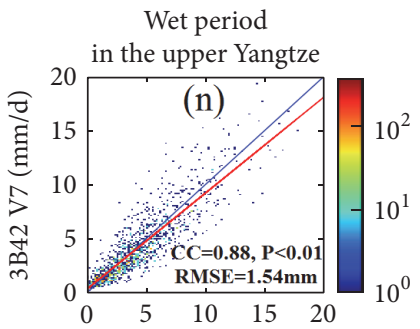

Observed precipitation (mm)

(n)

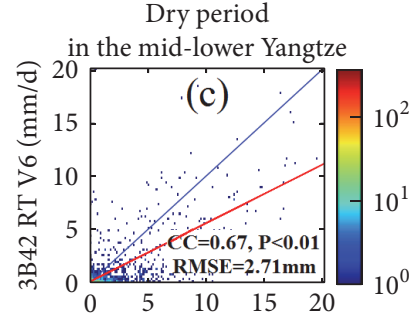

Observed precipitation $(\mathrm{mm})$

(c)

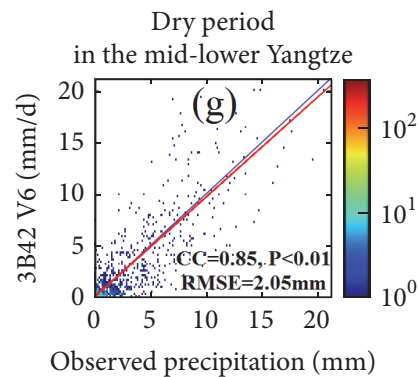

(g)

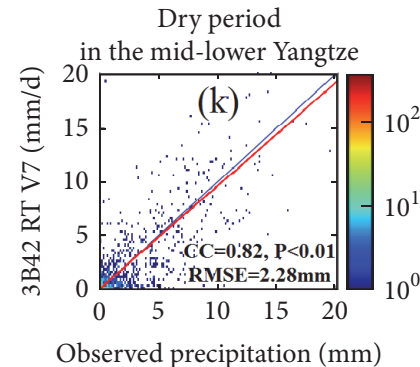

(k)

Dry period

in the mid-lower Yangtze

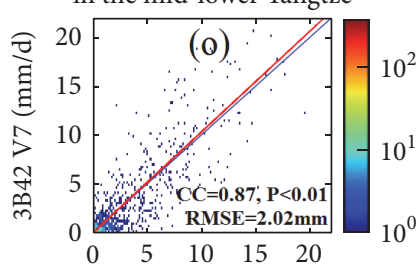

Observed precipitation $(\mathrm{mm})$

(o)

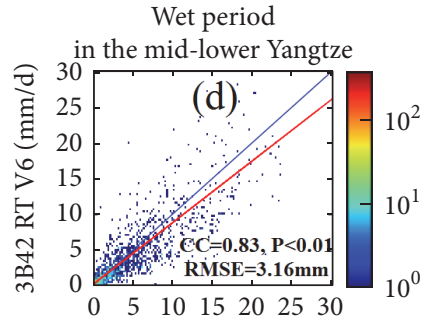

Observed precipitation $(\mathrm{mm})$

(d)

Wet period in the mid-lower Yangtze

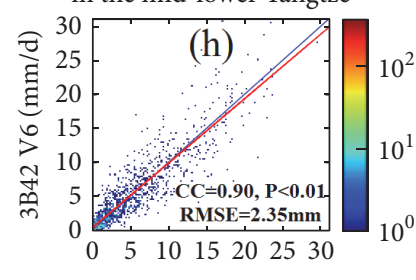

Observed precipitation $(\mathrm{mm})$

(h)

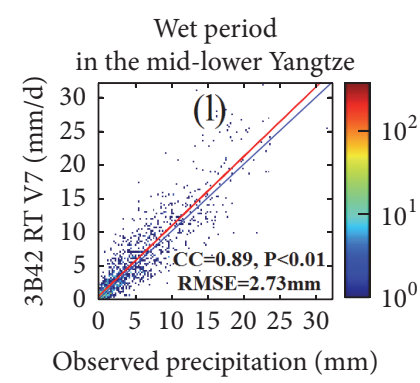

(1)

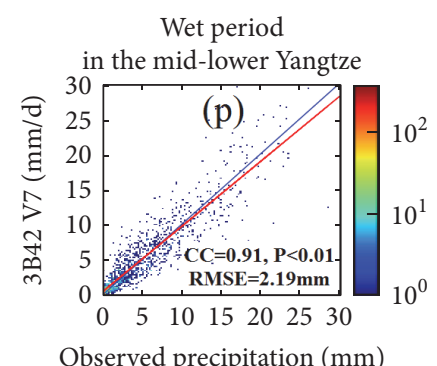

(p)

FIGURE 6: Scatter plots of TMPA versus observed daily mean precipitation for the dry period and wet period in the Yangtze River basin.

the V7 product, especially in the upper Yangtze reaches for the dry period. Similar results also can be found in previous studies; for example, Gao and Liu [40] revealed better agreement with gauge measurements over humid regions than that over arid regions in the Tibetan Plateau. Gu et al. [28] reported that the TRMM V6 data slightly overestimated rainfall during the wet season and underestimated rainfall during the dry season in the Yangtze River basin. Islam and Uyeda [35] indicated that the V5 data overestimated the rainfall during the premonsoon period and in dry regions but underestimated it during the monsoon period and in wet regions.

A noticeable improvement in satellite-based precipitation products has been made. Montero-Martínez et al. [52] conducted an evaluation of precipitation estimations in a complex topography and high elevation and they found that 2B31 TRMM data could be used in weather applications for the area with complex topographical characteristics and also as a tool in the diagnosis of individual rain events in other regions where there were no other data sources available. 


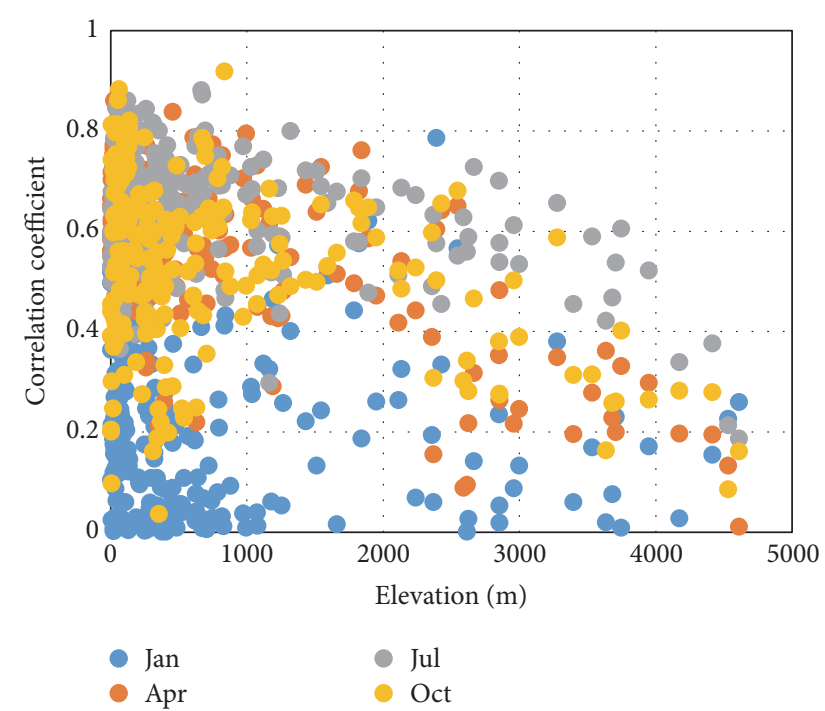

(a) RTV6

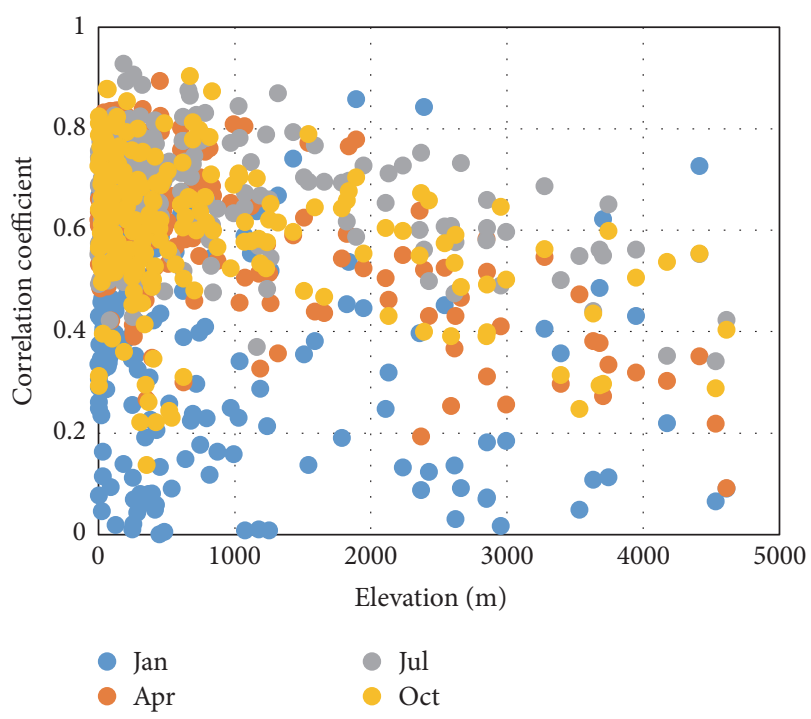

(c) V6

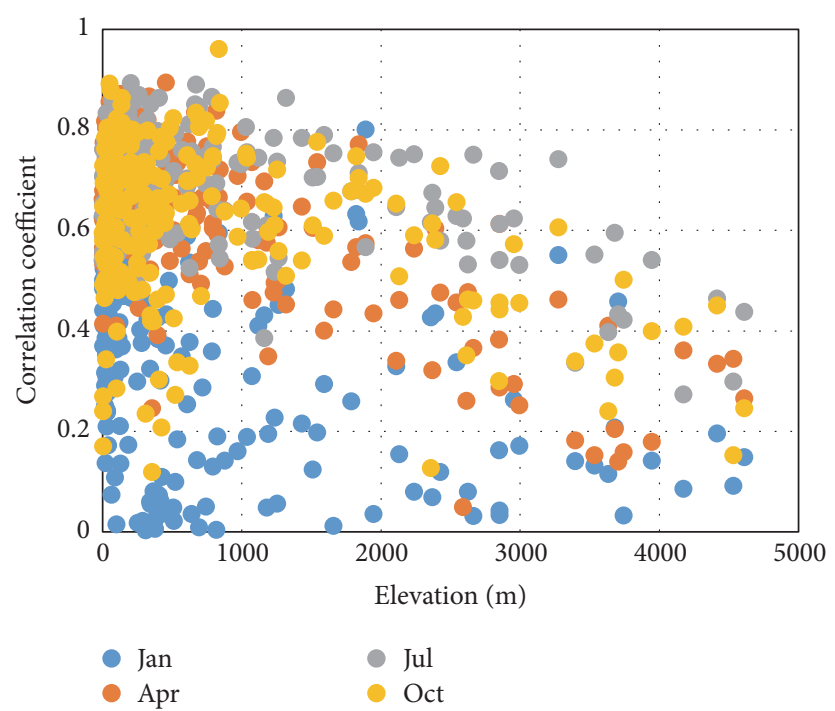

(b) RTV7

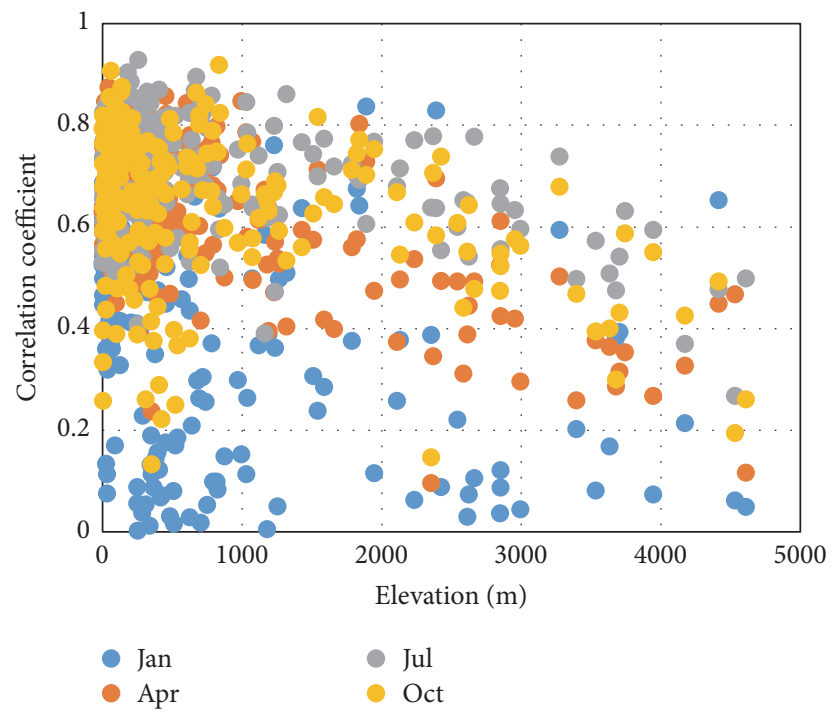

(d) V7

FIGURE 7: Seasonal distribution of correlation coefficient of TRMM precipitation and observed data with elevation.

While Yong et al. [32] thought the RTV7 represented a substantial improvement over the RTV6 in the low-latitude Mishui basin, such improvement was not found in the highlatitude Laohahe basin, which suggested that the RTV7 precipitation estimates still have much room for improvement at high latitudes.

The performance of TMPA precipitation estimation shows a downward trend with the increasing elevation in the Yangtze River basin in different seasons. The CC values vary from $0.41 \sim 0.93$ (500 m below) to $0.27 \sim 0.89$ (500 4000 m high) and $0.27 \sim 0.50$ (4000 $\mathrm{m}$ high) in July in the upper Yangtze reaches. Many studies indicated that the satellitebased precipitation has larger measurement uncertainties over complex terrains, inland water bodies, and high-latitude areas [40, 42], as the analysis by Gao and Liu [40] found that biases of TMPA and CMORPH present weak dependence on topography in the Tibetan Plateau, while Dinku et al.
[53] stated that satellite-based precipitation estimation is controlled by the orography. Gao and Liu [40] inferred that positive bias in TMPA RT products over the Tibetan Plateau may be attributable to the impact of topography on IR observations. Moreover, Gebregiorgis and Hossain [54] indicated that satellite rainfall uncertainty is dependent more on topography than the climate of the region in some areas.

\section{Conclusions}

The main objective of this study is to quantify evaluation of different TMPA precipitation products by using rain gauge data for the years of 2003 2010. We evaluated and compared the statistical characteristics of RTV6 (V6) and RTV7 (V7) over the Yangtze River basin. The main findings are summarized as follows. 


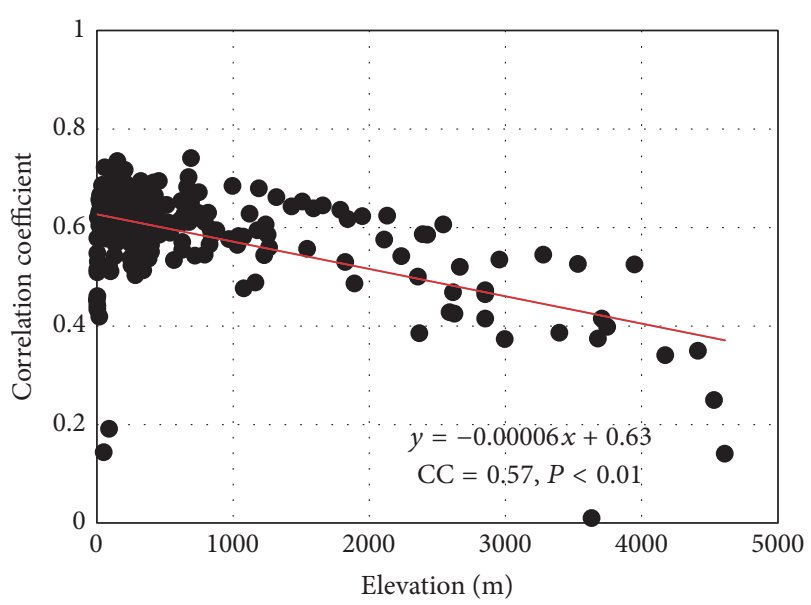

(a) RTV6

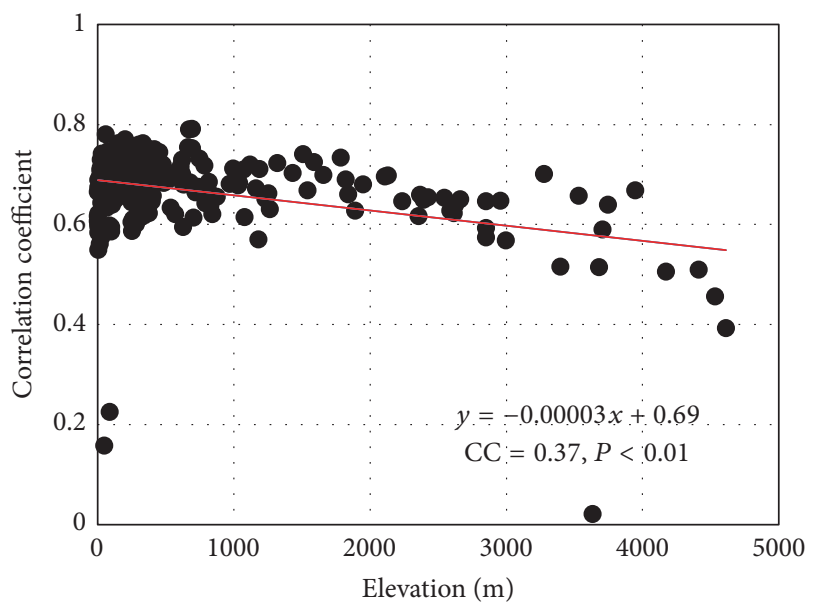

(c) V6

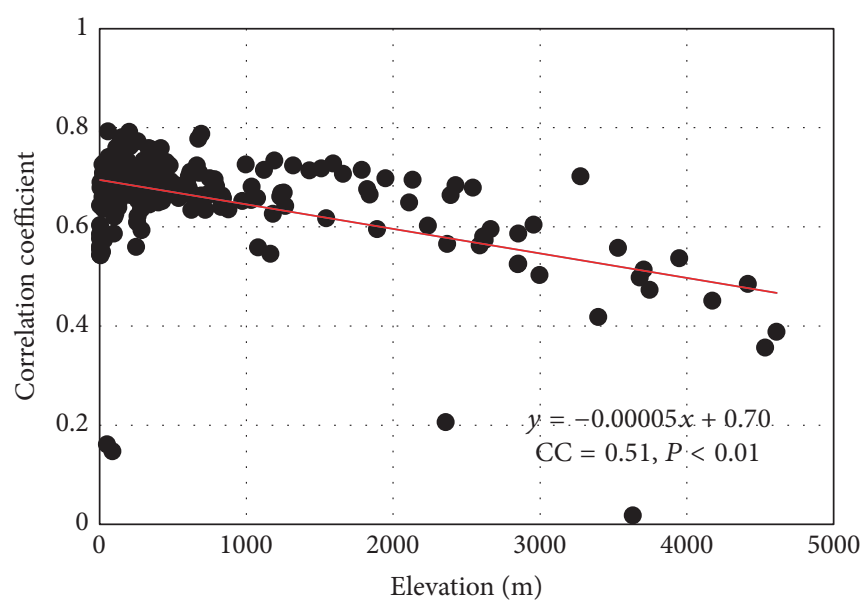

(b) RTV7

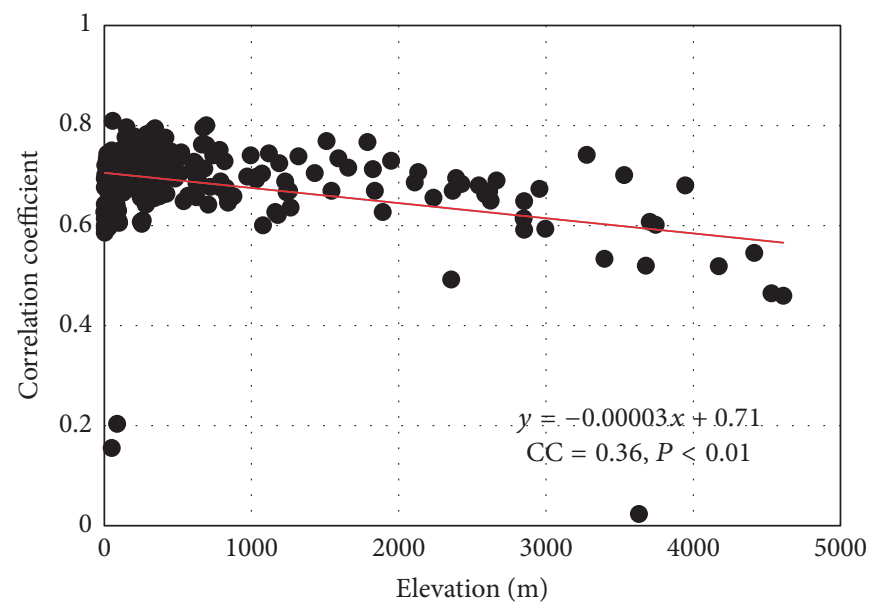

(d) V7

FIGURE 8: The correlativity between elevation and correlation coefficient of TRMM precipitation and observed data.

Both V6 and V7 have similar spatial patterns of precipitation biases in the Yangtze River basin and most of the precipitation bias ranges from $-10 \%$ to $10 \%$. The performance of the RTV7 (V7) precipitation products is generally better than that of RTV6 (V6) and the percentage of best performance for the RTV7 (V7) products is $36.70 \%$ (59.85\%), while it is $21.72 \%$ (54.79\%) for the RTV6 (V6) over the entire Yangtze River basin.

The monsoon climate might have significant impacts on the precipitation evaluation in the Yangtze River basin. Higher CC values can be found between the TMPA products and the observed precipitation during the wet period (CC ranges $0.75 \sim 0.91$ ) than that of the dry period (CC ranges $0.46 \sim 0.87$ ) in the Yangtze River basin, and average CC value between TMPA products and observed precipitation is 0.67 in July and it is 0.32 in January for the entire Yangtze River basin.

The performance of TMPA precipitation might be affected by the elevation in the Yangtze River basin. A downward trend for performance of the TMPA products with the increasing elevation can be found in the Yangtze River basin in different seasons. The correlation coefficient (CC) between the V7 and observed precipitation ranges $0.41 \sim 0.93$ and $0.27 \sim 0.89$ in the upper Yangtze reaches $500 \mathrm{~m}$ below and 500 4000 $\mathrm{m}$ high, respectively, while the CC decreases to $0.27 \sim 0.50$ when the stations are located $4000 \mathrm{~m}$ high.

This paper addresses knowledge gaps from previous studies by assessing the impacts of monsoon climate and elevation on the evaluation of TMPA precipitation products in the Yangtze River basin. The results quantify the evaluation of TMPA precipitation products based on different time scale in different areas in the Yangtze River basin. Outcomes of this work are expected to assist in answering the question regarding the performance of satellite precipitation in a complex climate and topography area.

\section{Competing Interests}

The authors declare that they have no competing interests.

\section{Acknowledgments}

This paper is financially supported by the State Key Development Program for Basic Research of China (Grant no. 
2012CB417006) and by National Natural Science Foundation of China (Grant nos. 51190090 and 41171020). Project was supported by Distinguished Young Scholars Fund of Nanjing Forestry University and by Open Research Fund Program of State Key Laboratory of Water Resources and Hydropower Engineering Science (Grant no. 2011B079), Key Laboratory of Watershed Geographic Sciences, Chinese Academy of Sciences (Grant no. WSGS2015005), the State Key Laboratory of Satellite Ocean Environment Dynamics, Second Institute of State Oceanic Administration, Six Talent Peaks Project in Jiangsu Province (Grant no. 2015-JY-017), and the Priority Academic Program Development of Jiangsu Higher Education Institutions (PAPD). The authors would like to thank the National Climate Centre in Beijing for providing valuable climate datasets.

\section{References}

[1] R. F. Adler, J.-J. Wang, G. Gu, and G. J. Huffman, "A ten-year tropical rainfall climatology based on a composite of TRMM products," Journal of the Meteorological Society of Japan, vol. 87, pp. 281-293, 2009.

[2] Z. Duan and W. G. M. Bastiaanssen, "First results from Version 7 TRMM 3B43 precipitation product in combination with a new downscaling-calibration procedure," Remote Sensing of Environment, vol. 131, pp. 1-13, 2013.

[3] S. Pombo and R. P. de Oliveira, "Evaluation of extreme precipitation estimates from TRMM in Angola," Journal of Hydrology, vol. 523, pp. 663-679, 2015.

[4] M. M. Rahman, D. S. Arya, N. K. Goel, and A. K. Mitra, "Rainfall statistics evaluation of ECMWF model and TRMM data over Bangladesh for flood related studies," Meteorological Applications, vol. 19, no. 4, pp. 501-512, 2012.

[5] M. Zhang, Y. C. Qi, and X. M. Hu, "Impact of East Asian winter monsoon on the Pacific storm track," Meteorological Applications, vol. 21, no. 4, pp. 873-878, 2014.

[6] V. M. Mantas, Z. Liu, C. Caro, and A. J. S. C. Pereira, "Validation of TRMM multi-satellite precipitation analysis (TMPA) products in the Peruvian Andes," Atmospheric Research, vol. 163, pp. 132-145, 2015.

[7] R. Shrivastava, S. K. Dash, M. N. Hegde, K. S. Pradeepkumar, and D. N. Sharma, "Validation of the TRMM multi satellite rainfall product 3B42 and estimation of scavenging coefficients for 131I and 137Cs using TRMM 3B42 rainfall data," Journal of Environmental Radioactivity, vol. 138, pp. 132-136, 2014.

[8] X.-H. Li, Q. Zhang, and C.-Y. Xu, "Suitability of the TRMM satellite rainfalls in driving a distributed hydrological model for water balance computations in Xinjiang catchment, Poyang lake basin," Journal of Hydrology, vol. 426-427, pp. 28-38, 2012.

[9] Q. Cao and Y. C. Qi, "The variability of vertical structure of precipitation in Huaihe River Basin of China: implications from long-term spaceborne observations with TRMM precipitation radar," Water Resources Research, vol. 50, no. 5, pp. 3690-3705, 2014.

[10] S.-J. Wu, H.-C. Lien, C.-T. Hsu, C.-H. Chang, and J.-C. Shen, "Modeling probabilistic radar rainfall estimation at ungauged locations based on spatiotemporal errors which correspond to gauged data," Hydrology Research, vol. 46, no. 1, pp. 39-59, 2015.

[11] K. Asghari and M. Nasseri, "Spatial rainfall prediction using optimal features selection approaches," Hydrology Research, vol. 46, no. 3, pp. 343-355, 2015.
[12] M. Shafiei, B. Ghahraman, B. Saghafian, S. Pande, S. Gharari, and K. Davary, "Assessment of rain-gauge networks using a probabilistic GIS based approach," Hydrology Research, vol. 45, no. 4-5, pp. 551-562, 2014.

[13] S. J. Wu, C. H. Chang, C. T. Hsu, and J. C. Shen, "An evaluation framework for identifying the optimal rain-gauge network based on spatiotemporal variation in quantitative precipitation estimation," Hydrology Research, 2016.

[14] C. Chen, Z. Yu, L. Li, and C. Yang, "Adaptability evaluation of TRMM satellite rainfall and its application in the dongjiang river basin," Procedia Environmental Sciences A, vol. 10, pp. 396402, 2011.

[15] J. Meng, L. Li, Z. Hao, J. Wang, and Q. Shao, "Suitability of TRMM satellite rainfall in driving a distributed hydrological model in the source region of Yellow River," Journal of Hydrology, vol. 509, pp. 320-332, 2014.

[16] P. D. Wagner, P. Fiener, F. Wilken, S. Kumar, and K. Schneider, "Comparison and evaluation of spatial interpolation schemes for daily rainfall in data scarce regions," Journal of Hydrology, vol. 464-465, pp. 388-400, 2012.

[17] C. B. Moffitt, F. Hossain, R. F. Adler, K. K. Yilmaz, and H. F. Pierce, "Validation of a TRMM-based global flood detection system in Bangladesh," International Journal of Applied Earth Observation and Geoinformation, vol. 13, no. 2, pp. 165-177, 2011.

[18] A. K. Sahoo, J. Sheffield, M. Pan, and E. F. Wood, "Evaluation of the Tropical Rainfall Measuring Mission Multi-Satellite Precipitation Analysis (TMPA) for assessment of large-scale meteorological drought," Remote Sensing of Environment, vol. 159, pp. 181-193, 2015.

[19] X. Xue, Y. Hong, A. S. Limaye et al., "Statistical and hydrological evaluation of TRMM-based Multi-satellite Precipitation Analysis over the Wangchu Basin of Bhutan: are the latest satellite precipitation products $3 \mathrm{~B} 42 \mathrm{~V} 7$ ready for use in ungauged basins?" Journal of Hydrology, vol. 499, pp. 91-99, 2013.

[20] D. C. Buarque, R. C. D. De Paiva, R. T. Clarke, and C. A. B. Mendes, "A comparison of Amazon rainfall characteristics derived from TRMM, CMORPH and the Brazilian national rain gauge network," Journal of Geophysical Research Atmospheres, vol. 116, no. 19, Article ID D19105, 2011.

[21] L. Li, C. S. Ngongondo, C.-Y. Xu, and L. Gong, "Comparison of the global TRMM and WFD precipitation datasets in driving a large-scale hydrological model in southern Africa," Hydrology Research, vol. 44, no. 5, pp. 770-788, 2013.

[22] A. Sealy, G. S. Jenkins, and S. C. Walford, "Seasonal/regional comparisons of rain rates and rain characteristics in West Africa using TRMM observations," Journal of Geophysical ResearchAtmospheres, vol. 108, no. 10, 2003.

[23] D. B. Wolff and B. L. Fisher, "Comparisons of instantaneous TRMM ground validation and sattellite rain-rate estimates at different spatial scales," Journal of Applied Meteorology and Climatology, vol. 47, no. 8, pp. 2215-2237, 2008.

[24] H. Xu, C.-Y. Xu, N. R. Sælthun, B. Zhou, and Y. Xu, "Evaluation of reanalysis and satellite-based precipitation datasets in driving hydrological models in a humid region of Southern China," Stochastic Environmental Research and Risk Assessment, vol. 29, no. 8, pp. 2003-2020, 2015.

[25] H. Xu, C.-Y. Xu, N. R. Sælthun, Y. Xu, B. Zhou, and H. Chen, "Entropy theory based multi-criteria resampling of rain gauge networks for hydrological modelling-a case study of humid area in southern China," Journal of Hydrology, vol. 525, pp. 138151, 2015. 
[26] K. Tong, F. Su, D. Yang, and Z. Hao, "Evaluation of satellite precipitation retrievals and their potential utilities in hydrologic modeling over the Tibetan Plateau," Journal of Hydrology, vol. 519, pp. 423-437, 2014.

[27] B. Collischonn, W. Collischonn, and C. E. M. Tucci, "Daily hydrological modeling in the Amazon basin using TRMM rainfall estimates," Journal of Hydrology, vol. 360, no. 1-4, pp. 207-216, 2008.

[28] H.-H. Gu, Z.-B. Yu, C.-G. Yang, Q. Ju, B.-H. Lu, and C. Liang, "Hydrological assessment of TRMM rainfall data over Yangtze River Basin," Water Science and Engineering, vol. 3, no. 4, pp. 418-430, 2010.

[29] Y. Chen, E. E. Ebert, K. J. E. Walsh, and N. E. Davidson, "Evaluation of TRMM 3B42 precipitation estimates of tropical cyclone rainfall using PACRAIN data," Journal of Geophysical Research-Atmospheres, vol. 118, no. 5, pp. 2184-2196, 2013.

[30] H. Zhao, S. Yang, Z. Wang, X. Zhou, Y. Luo, and L. Wu, "Evaluating the suitability of TRMM satellite rainfall data for hydrological simulation using a distributed hydrological model in the Weihe River catchment in China," Journal of Geographical Sciences, vol. 25, no. 2, pp. 177-195, 2015.

[31] L. Qiao, Y. Hong, S. Chen, C. B. Zou, J. J. Gourley, and B. Yong, "Performance assessment of the successive Version 6 and Version 7 TMPA products over the climate-transitional zone in the southern Great Plains, USA," Journal of Hydrology, vol. 513, pp. 446-456, 2014.

[32] B. Yong, B. Chen, J. J. Gourley et al., "Intercomparison of the Version-6 and Version-7 TMPA precipitation products over high and low latitudes basins with independent gauge networks: is the newer version better in both real-time and post-real-time analysis for water resources and hydrologic extremes?" Journal of Hydrology, vol. 508, pp. 77-87, 2014.

[33] S. I. Khan, Y. Hong, J. J. Gourley, M. U. K. Khattak, B. Yong, and H. J. Vergara, "Evaluation of three high-resolution satellite precipitation estimates: potential for monsoon monitoring over Pakistan," Advances in Space Research, vol. 54, no. 4, pp. 670684, 2014.

[34] E. Habib, A. Henschke, and R. F. Adler, "Evaluation of TMPA satellite-based research and real-time rainfall estimates during six tropical-related heavy rainfall events over Louisiana, USA," Atmospheric Research, vol. 94, no. 3, pp. 373-388, 2009.

[35] M. N. Islam and H. Uyeda, "Use of TRMM in determining the climatic characteristics of rainfall over Bangladesh," Remote Sensing of Environment, vol. 108, no. 3, pp. 264-276, 2007.

[36] X. Li, Q. Zhang, and X. Ye, "Dry/wet conditions monitoring based on TRMM rainfall data and its reliability validation over poyang lake basin, China," Water, vol. 5, no. 4, pp. 1848-1864, 2013.

[37] M. Almazroui, "Calibration of TRMM rainfall climatology over Saudi Arabia during 1998-2009," Atmospheric Research, vol. 99, no. 3-4, pp. 400-414, 2011.

[38] Z. Liu, "Comparison of versions 6 and 7 3-hourly TRMM multi-satellite precipitation analysis (TMPA) research products," Atmospheric Research, vol. 163, pp. 91-101, 2015.

[39] Y. Guan, X. Zhang, F. Zheng, and B. Wang, "Trends and variability of daily temperature extremes during 1960-2012 in the Yangtze River Basin, China," Global and Planetary Change, vol. 124, pp. 79-94, 2015.

[40] Y. C. Gao and M. F. Liu, "Evaluation of high-resolution satellite precipitation products using rain gauge observations over the Tibetan Plateau," Hydrology and Earth System Sciences, vol. 17, no. 2, pp. 837-849, 2013.
[41] Z.-C. Hao, K. Tong, X.-L. Liu, and L.-L. Zhang, "Capability of TMPA products to simulate streamflow in upper Yellow and Yangtze River basins on Tibetan Plateau," Water Science and Engineering, vol. 7, no. 3, pp. 237-249, 2014.

[42] Z. Li, D. Yang, and Y. Hong, "Multi-scale evaluation of highresolution multi-sensor blended global precipitation products over the Yangtze River," Journal of Hydrology, vol. 500, pp. 157$169,2013$.

[43] W. Xie, Y. Fu, Y. Li, J. Li, Y. Li, and Q. Yue, "Cryogenic THGEMGPM for the readout of scintillation light from liquid argon," Nuclear Instruments and Methods in Physics Research Section A: Accelerators, Spectrometers, Detectors and Associated Equipment, vol. 774, pp. 120-126, 2015.

[44] D. Long, Y. Yang, Y. Wada et al., "Deriving scaling factors using a global hydrological model to restore GRACE total water storage changes for China's Yangtze River Basin," Remote Sensing of Environment, vol. 168, pp. 177-193, 2015.

[45] T. Islam, M. A. Rico-Ramirez, D. Han, P. K. Srivastava, and A. M. Ishak, "Performance evaluation of the TRMM precipitation estimation using ground-based radars from the GPM validation network," Journal of Atmospheric and Solar-Terrestrial Physics, vol. 77, pp. 194-208, 2012.

[46] G.-J. Zhao, G. Hörmann, N. Fohrer, J.-F. Gao, J.-Q. Zhai, and Z.-X. Zhang, "Spatial and temporal characteristics of wet spells in the Yangtze River Basin from 1961 to 2003," Theoretical and Applied Climatology, vol. 98, no. 1-2, pp. 107-117, 2009.

[47] S. Chen, Y. Hong, Q. Cao et al., "Similarity and difference of the two successive V6 and V7 TRMM multisatellite precipitation analysis performance over China," Journal of Geophysical Research Atmospheres, vol. 118, no. 23, pp. 13060-13074, 2013.

[48] B. D. Su, T. Jiang, and W. B. Jin, "Recent trends in observed temperature and precipitation extremes in the Yangtze River basin, China," Theoretical and Applied Climatology, vol. 83, no. 1-4, pp. 139-151, 2006.

[49] J. He, J. Ju, Z. Wen, J. Lü, and Q. Jin, "A review of recent advances in research on Asian monsoon in China," Advances in Atmospheric Sciences, vol. 24, no. 6, pp. 972-992, 2007.

[50] R. Huang, J. Chen, and G. Huang, "Characteristics and variations of the East Asian monsoon system and its impacts on climate disasters in China," Advances in Atmospheric Sciences, vol. 24, no. 6, pp. 993-1023, 2007.

[51] Q. Zhang, C.-Y. Xu, T. Jiang, and Y. Wu, "Possible influence of ENSO on annual maximum streamflow of the Yangtze River, China," Journal of Hydrology, vol. 333, no. 2-4, pp. 265-274, 2007.

[52] G. Montero-Martínez, V. Zarraluqui-Such, and F. GarcíaGarcía, "Evaluation of 2B31 TRMM-product rain estimates for single precipitation events over a region with complex topographic features," Journal of Geophysical Research Atmospheres, vol. 117, no. 2, Article ID D02101, 2012.

[53] T. Dinku, S. Chidzambwa, P. Ceccato, S. J. Connor, and C. F. Ropelewski, "Validation of high-resolution satellite rainfall products over complex terrain," International Journal of Remote Sensing, vol. 29, no. 14, pp. 4097-4110, 2008.

[54] A. S. Gebregiorgis and F. Hossain, "Understanding the dependence of satellite rainfall uncertainty on topography and climate for hydrologic model simulation," IEEE Transactions on Geoscience and Remote Sensing, vol. 51, no. 1, pp. 704-718, 2013. 

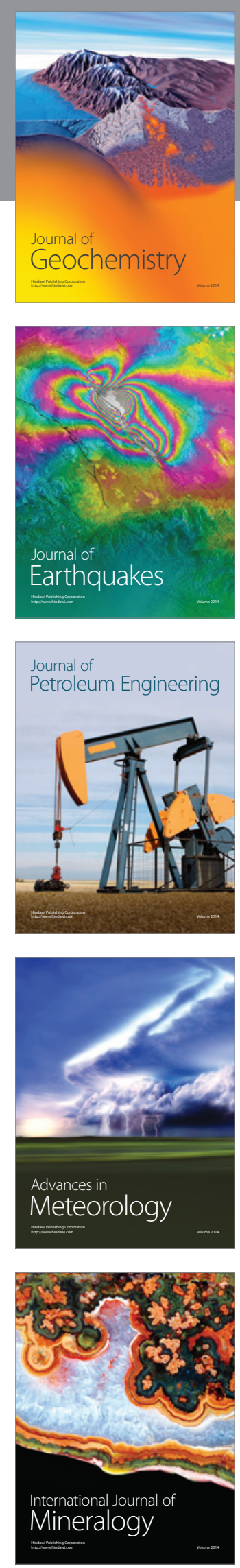
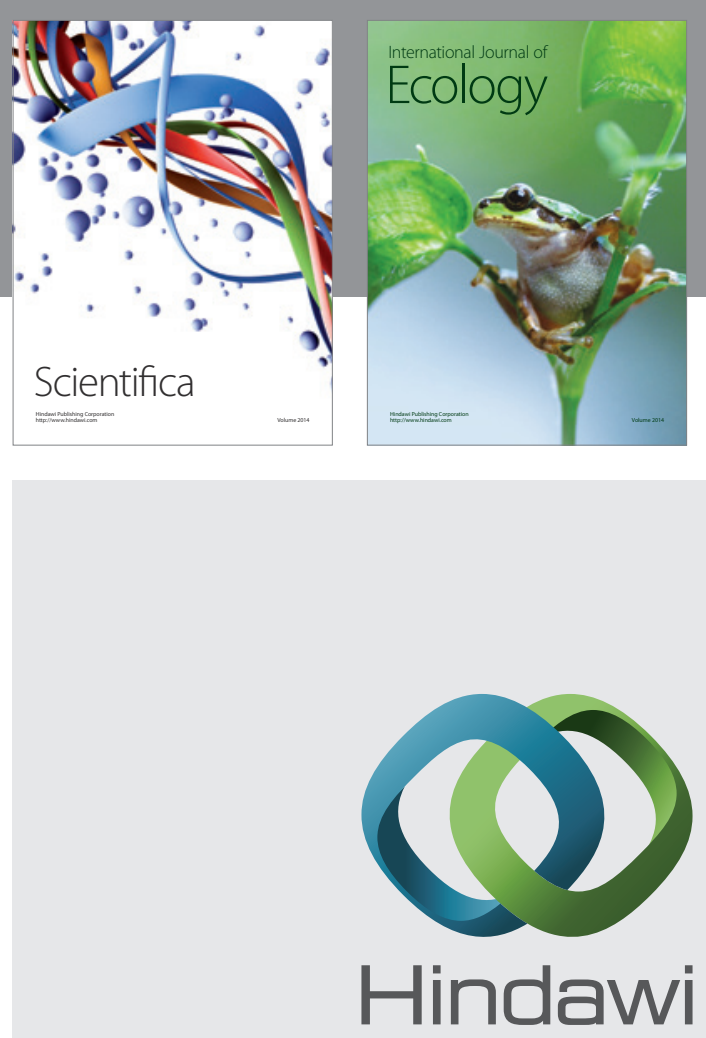

Submit your manuscripts at

http://www.hindawi.com
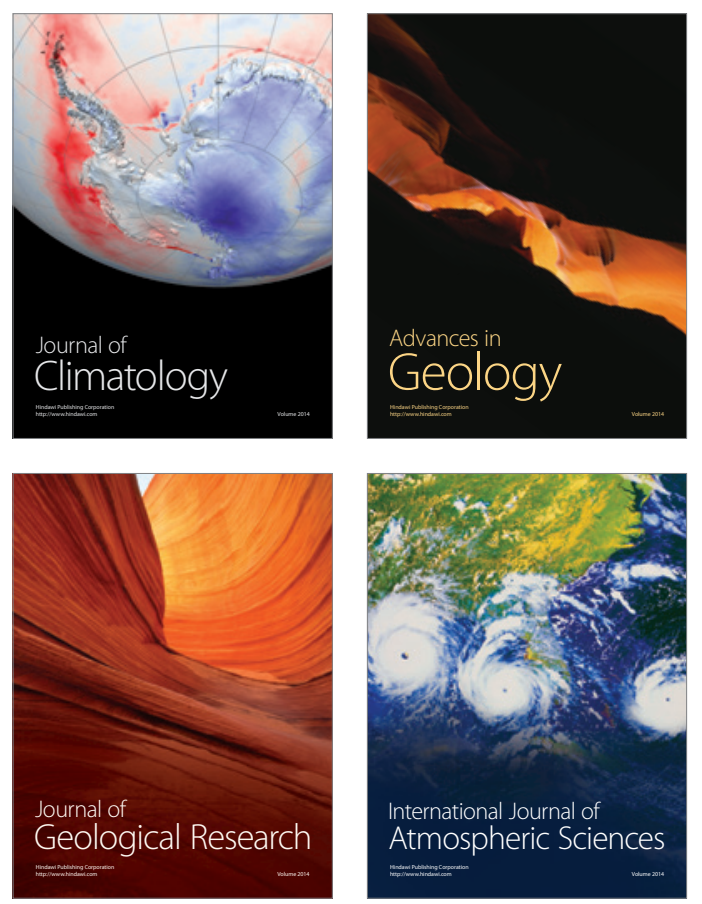

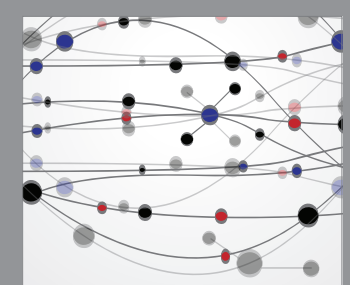

The Scientific

\section{World Journal}
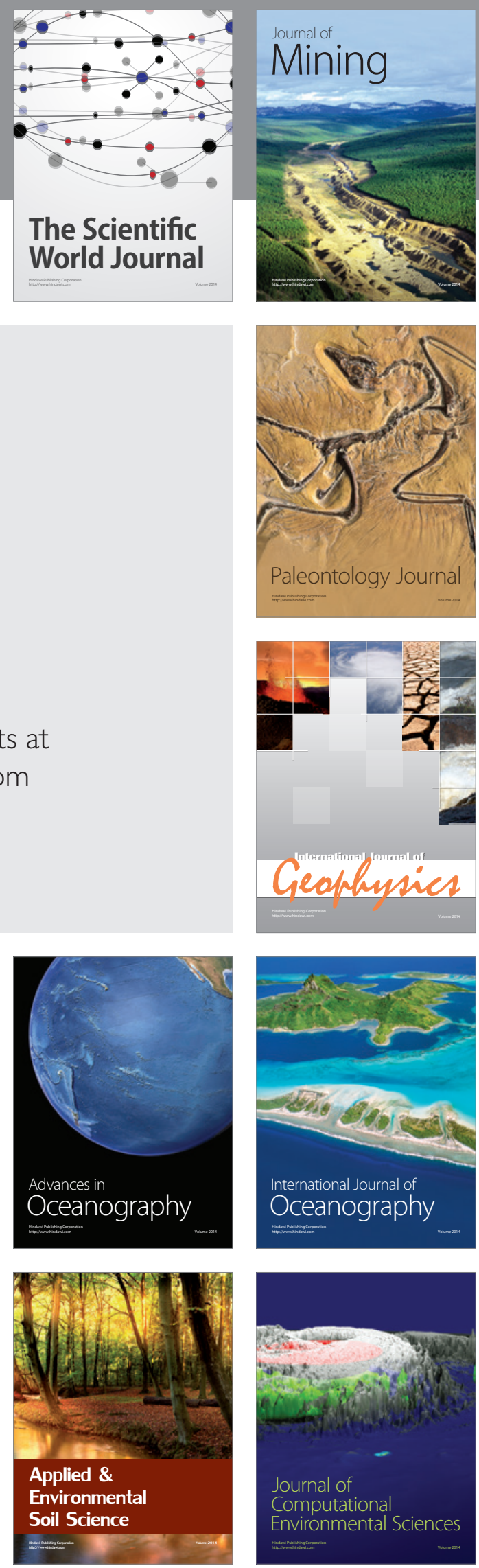